\title{
Consumo voluntário e digestibilidade de fenos triturados de gramíneas tropicais em caprinos ${ }^{1}$
}

\section{Emerson Moreira de Aguiar², Guilherme Ferreira da Costa Lima ${ }^{3}$, Mércia Virgínia Ferreira dos Santos ${ }^{4}$, Francisco Fernando Ramos de Carvalho ${ }^{4}$, Henrique Rocha de Medeiros ${ }^{5}$, Francisco Canindé Maciel ${ }^{3}$, Ana Cristina da Costa Januário 6}

${ }^{1}$ Parte da tese apresentada pelo primeiro autor ao Programa de Doutorado Integrado em Zootecnia da UFRPE. Projeto financiado pela FINEP/CONECIT - RN.

2 Departamento de Agropecuária - UFRN - Natal - RN

3 EMBRAPA/EMPARN - Natal - RN.

${ }^{4} D Z / U F R P E$ - Recife-PE.

5 Bolsista CNPq/EMPARN - Natal-RN.

${ }^{6}$ Estudante do curso de Zootecnia - UFRN e Bolsista CNPq - Natal-RN.

RESUMO - Objetivou-se determinar o consumo voluntário e a digestibilidade dos nutrientes de fenos triturados de milheto, sorgo sudanense, capim-elefante e cultivares de sorgo forrageiro SF-25 e IPA-467-4-2 em caprinos. Utilizaram-se 25 animais (18 meses de idade e 19,5 kg de PV inicial) distribuídos em um delineamento em blocos completos casualizados, com cinco tratamentos e cinco repetições. Os consumos de MS (CMS) e MO (CMO), quando expressos em porcentagem de peso vivo (\%PV), não foram influenciados pelos tratamentos. O CMS representou, respectivamente, 2,41; 2,33; 2,25; 1,82 e 1,85\% do PV dos caprinos. Os consumos voluntários de PB (\%PV) evidenciaram diferenças significativas para os fenos de milheto e sorgo sudanense, que foram superiores aos de capim-elefante e aos dos sorgos SF-25 e IPA-467-4-2. Os consumos de FDN não diferiram entre os fenos e variaram de 236,14 a 322,10 g/dia, representando 1,25 a 1,61\% do PV dos caprinos. A digestibilidade aparente da MS dos fenos não sofreu influência significativa e variou de 49,87 a 55,90\%. Para a digestibilidade da PB (DPB), não foram constatadas diferenças significativas entre os fenos de milheto, sorgo sudanense, capim-elefante e sorgo SF-25. A digestibilidade da FDN (DFDN), no entanto, apresentou variação significativa entre os fenos do milheto $(64,44 \%)$ e sorgo IPA-467-4-2 (54,72\%). Os valores de digestibilidade, indicativos de qualidade, dos fenos triturados das cinco gramíneas foram aproximados e as diferenças requerem a realização de ensaios de desempenho para suas comprovações.

Palavras-chave: fenação, forragem, nutrição animal, Pennisetum, Sorghum

\section{Intake and apparent digestibility of chopped grass hays fed to goats}

\begin{abstract}
The objective of this trial was to investigate intake and apparent digestibility of nutrients on goats fed one of the following chopped grass hays: pearl millet (PMH), sudangrass ( $\mathrm{SH})$, elephantgrass (EH) or two cultivars of forage sorghum (FSH1 and FSH2). Twenty-five goats averaging 18 months of age and $19.5 \mathrm{~kg}$ of body weight were assigned to a completely randomized block design with five treatments and five replicates. DM intake (DMI), expressed as percentage of body weight (\% BW), did not differ and averaged $2.41,2.33,2.25,1.82$, and $1.85 \%$, respectively, for PMH, SH, EH, FSH1, and FSH2. The same was observed for the intakes of OM and NDF. However, CP intake as \% BW was greater on goats fed PMH and SH than on those fed EH, FSH1, and FSH2. No significant differences were observed for the apparent total tract digestibility of DM that varied from 49.87 to $55.90 \%$ across hays. CP digestibility was lowest on FSH2, intermediate on SH and FSH1, and greatest on PMH and EH while that of NDF differed significantly only by comparing PMH (64.44\%) with FSH2 (54.72\%). It can be concluded that the overall nutritional quality of all five hays were similar and further research is required to verify potential differences in animal performance among these forage sources.
\end{abstract}

Key Words: forage, haymaking, Pennisetum, ruminant nutrition, Sorghum

\section{Introdução}

As pastagens constituem o alicerce da pecuária no Brasil. Entretanto, não sustentam altos níveis de produção durante todo o ano, em virtude das interações entre fatores de ambiente e de manejo, podendo também apresentar grande variação no seu valor nutritivo (Moreira et al., 2001). Assim, a utilização de forragens conservadas consiste em 
altemativa para amenizar os problemas decorrentes da estacionalidade da produção forrageira.

Segundo Reis et al. (2001), o manejo de forrageiras de alta qualidade para a produção de fenos de elevado valor nutritivo é essencial para suprir as deficiências qualiquantitativas de alimentos observadas nos períodos de seca. Como a capacidade de suporte das pastagens nativas é baixa e a área dos estabelecimentos rurais e das pastagens cultivadas no Nordeste semi-árido é pequena, são limitadas as alternativas para o desenvolvimento de uma pecuária sustentável para a agricultura familiar, fora da produção intensiva de forragens e da utilização de práticas de armazenamento (Lima et al., 2002).

No Brasil, as forrageiras do gênero Cynodon são as mais utilizadas na produção de feno, tendo em vista seu elevado potencial de produção e sua qualidade (Cavalcante et al., 2004). No entanto, como a maioria dos agricultores familiares do semi-árido possui estabelecimentos com áreas restritas e não cultiva gramíneas mais adequadas à fenação, torna-se necessário viabilizar alternativas de produção e conservação de forragens capazes de garantir o suporte alimentar dos rebanhos no período seco.

Entre os fatores que afetam a qualidade da forragem, Sollenberger \& Cherney (1995) incluíram o valor nutritivo e o consumo. De acordo com esses autores, o valor nutritivo da forragem engloba sua composição química e a digestibilidade e natureza dos produtos digeridos.

Cherney et al. (1990a) afirmaram que o consumo voluntário da forragem é função de sua digestibilidade e características químicas, físicas e morfológicas. Kozloski et al. (2006) reforçaram que o consumo depende da digestibilidade e degradabilidade da parede celular e da taxa de passagem do alimento pelo trato digestivo.

No entanto, de acordo com Van Soest (1994), medidas de digestibilidade têm contribuído significativamente para o desenvolvimento de sistemas visando estimar o valor nutritivo dos alimentos. Esse autor destaca que a morfologia das plantas pode afetar a relaçãoconsumo $\times$ digestibilidade, pois, em níveis de consumo ad libitum ou com restrição, a oportunidade de seleção pode diminuir ou aumentar as diferenças entre forragens.

Este trabalho foi realizado com o objetivo de determinar o consumo voluntário e a digestibilidade dos nutrientes dos fenos triturados de diferentes gramíneas tropicais, em caprinos.

\section{Material e Métodos}

O experimento foi conduzido na Estação Experimental Felipe Camarão, em São Gonçalo do Amarante - RN (latitude $05^{\circ} 4^{\prime} \mathrm{S}$, longitude de $35^{\circ} 20^{\prime} \mathrm{O}$ e altitude média de $15 \mathrm{~m}$ ), no mês de abril de 2004. Foram utilizados 25 cabritos machos, castrados, sem raça definida, com 18 meses de idade e peso vivo inicial de $19,5 \pm 1,5 \mathrm{~kg}$, distribuídos em blocos completos casualizados, com cinco tratamentos e cinco repetições.

O período experimental teve duração de 19 dias (05/04 a 23/04/04), sendo 14 para adaptação dos animais aos tratamentos e às gaiolas de metabolismo e cinco para a coleta de dados.

Todos os animais foram pesados, vermifugados e receberam dose de suplemento vitamínico (ADE) uma semana antes do início do experimento. Os cabritos foram mantidos em gaiolas individuais de metabolismo $(1,2 \mathrm{~m}$ comprimento x $0,8 \mathrm{~m}$ largura), providas de comedouros, bebedouros e saleiros, acopladas com bandejas para coleta de fezes e urina.

Os tratamentos consistiram de fenos triturados de cinco gramíneas: milheto cv. IPA-Bulk-1, Pennisetum americanum (L.) Leeke, sorgo sudanense cv. Sudan-4202, Sorghum sudanense (Piper) Stapf., capim-elefante cv. Cameroon, Pennisetum purpureum Schum e sorgo forrageiro, Sorghum bicolor(L.) Moench., cultivares SF-25 e IPA-467-4-2, cujas composições bromatológicas encontram-se na Tabela 1.

Tabela 1 - Composição bromatológica (\% da MS) dos fenos triturados das gramíneas forrageiras

Table 1 - Chemical composition of chopped grass hays (\% of DM)

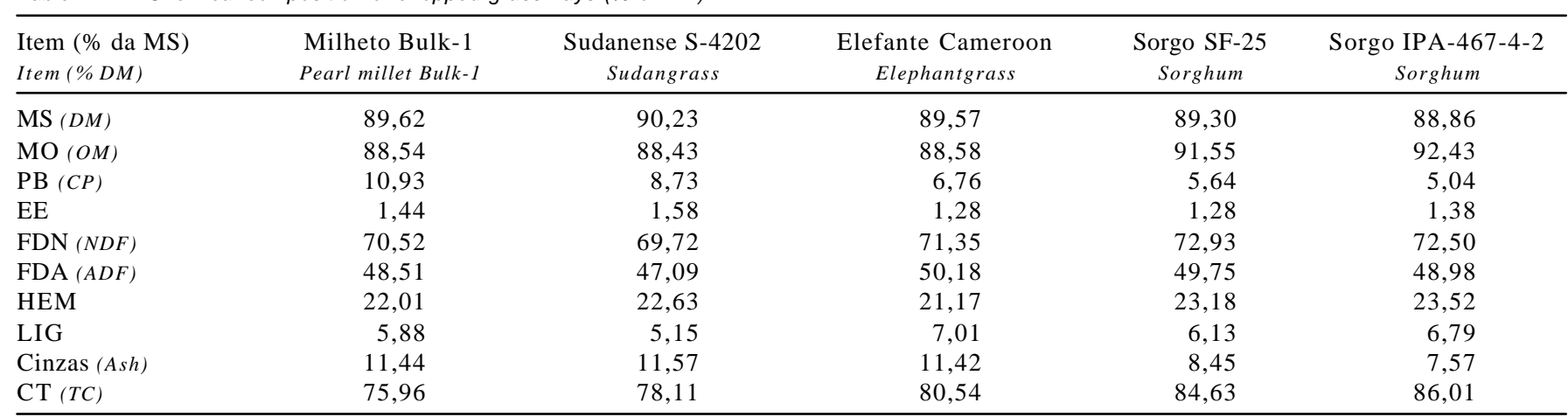


Para o manejo geral dos animais, a coleta e o processamento das amostras para determinação do consumo voluntário e da digestibilidade dos nutrientes, foram adotados os mesmos procedimentos descritos por Moore (1981). O tempo de armazenamento dos fenos utilizados nesse experimento foi dois anos, sendo conservados em armazém coberto, acondicionados em sacos de polietileno sobre estrados de madeira e removidos a cada quatro meses para inspeção e limpeza do armazém.

Os fenos foram triturados conforme descrito por Aguiar (2005) e fornecidos duas vezes ao dia, à vontade, às 7 (50\%) e 15 h (50\%). Nos 30 dias que antecederam o experimento, os cabritos foram confinados em um curral e alimentados com feno de capim-elefante e sal mineral comercial.

Nos períodos de adaptação (14 dias) e coleta (cinco dias), os cabritos foram alimentados exclusivamente com os fenos triturados, fornecidos ad libitum (20\% de sobras) de acordo com o tratamento.

Uma amostra representativa (300 g) do feno fornecido foi retirada de cada repetição em todos os dias do período de coleta. As sobras dos alimentos foram recolhidas diariamente e, após a pesagem, formaram uma amostra composta por unidade experimental. A determinação do consumo dos fenos foi realizada mediante a pesagem do oferecido e das sobras, no período do $15 \underline{0}$ ao 19 o dia.

As fezes foram coletadas e pesadas diariamente (às $7 \mathrm{~h}$ ) do $15 \underline{0}$ ao 19 으 dia. Após a homogeneização do material, retirou-se uma alíquota diária de $10 \%$ para preparação de uma amostra composta por animal, que foi armazenada em freezer a $-5^{\circ} \mathrm{C}$.

Ao término do ensaio, as amostras das fezes foram descongeladas à temperatura ambiente; em seguida, procedeu-se à pré-secagem das fezes, dos fenos ofertados e das sobras em estufa de ventilação forçada a $55^{\circ} \mathrm{C}$, por 72 horas. As amostras foram trituradas em moinho tipo Willey, com peneira de $1 \mathrm{~mm}$ para determinação dos teores de MS, cinzas, PB e EE, conforme descrito por Silva \& Queiroz (2002). A determinação dos valores de FDN foi realizada de acordo com o método descrito por Van Soest et al. (1991). Os valores de NDT foram calculados de acordo com Sniffen et al. (1992).

O programa SAS (1995) foi utilizado para a realização da análise estatística, sendo as médias comparadas pelo teste Tukey a $5 \%$ de probabilidade.

\section{Resultados e Discussão}

Houve diferença significativa no consumo de nutrientes $(\mathrm{P}<0,05)$ dos fenos triturados das forrageiras em avaliação (Tabela 2).
Os consumos de MS (CMS) e MO (CMO), quando expressos em porcentagem de peso vivo (\%PV), não diferiram entre os tratamentos. O CMS representou, respectivamente, 2,$41 ; 2,33 ; 2,25 ; 1,82$ e 1,85\% do PV (Tabela 2) para os fenos de milheto, sorgo sudanense, capim-elefante e sorgos SF-25 e IPA-467-4-2.

Avaliando o consumo e a digestibilidade de fenos de sorgo sudanense e milheto ofertados ad libitum a ovinos, Cherney et al. (1990a) obtiveram consumos de MO de 2,09 e 2,20\% do PV, respectivamente, bem próximos aos registrados nesta pesquisa $(2,07$ e $2,15 \%)$. Trabalhando com fenos de milheto com ovinos, Cherney et al. (1990b) obtiveram CMS médio de 2,16\% do PV.

Kozloski et al. (2006) relataram consumos médios de MS do feno de capim-elefante anão por ovinos, com diferentes níveis de oferta (1,5\% PV até ad libitum), da ordem de $2,29 \% \mathrm{PV}$, pouco superior ao percentual obtido nesse trabalho $(2,25 \%)$. Por outro lado, valores bem mais expressivos de CMS de fenos de capim-elefante são descritos na literatura. Aguiar et al. (2001) avaliaram fenos de capim-elefante com 30 a 91 dias de idade e obtiveram CMS com ovinos de 872,1 a $397,3 \mathrm{~g} / \mathrm{dia}(3,91$ a 2,37\% PV). Utilizando o mesmo tipo de feno com 50 dias de idade, Camurça et al. (2002) também relataram CMS em torno de $871,4 \mathrm{~g} / \mathrm{dia}(3,14 \% \mathrm{PV})$. Os menores consumos obtidos neste trabalho podem ser atribuídos à baixa relação folha/colmo do capim-elefante utilizado no preparo do feno $(0,69)$, conforme Aguiar (2005), à seletividade alimentar dos caprinos e ao longo período (dois anos) de armazenamento dos fenos.

Os consumos de MS obtidos para os fenos dos sorgos SF-25 e IPA-467-4-2 (Tabela 2) foram inferiores aos relatados por Distel et al. (1994), de $472 \mathrm{~g} / \mathrm{dia}$, e Blummel et al. (2003), de 47,05 g/kg PV0,75. Os sorgos avaliados apresentaram as menores relações $\mathrm{F} / \mathrm{C}(0,48$ e 0,38$)$, menores concentrações de PB $(5,64$ e 5,04\%) e maiores teores de FDN, em função da idade de corte, o que, decisivamente, influenciou o consumo das forragens (Aguiar, 2005).

O valor médio do consumo de MS dos fenos avaliados $\left(44,75 \mathrm{~g} / \mathrm{kg}^{0,75}\right)$ pode ser considerado baixo, em comparação à média observada por Reid et al. (1988) em 57 ensaios de consumo de MS com ovinos $\left(65,7 \mathrm{~g} / \mathrm{kg}^{0,75}\right)$.

Considerando os baixos consumos de MS e MO obtidos e a possibilidade de utilização desses fenos triturados como volumosos básicos para ruminantes, deve-se considerar a possibilidade da suplementação desses alimentos com concentrados energéticos ou protéicos com vistas a incrementar a ingestão de MS. No entanto, a utilização convencional de concentrados normalmente provoca diminuição do consumo da forragem (Hodgson, 1990). De acordo com Moore \& Kunkle (1995), a razão DMO/PB da 
Tabela 2 - Consumos voluntários diários dos nutrientes de fenos triturados de gramíneas tropicais em caprinos Table 2 - Daily nutrient intake of different chopped grass hays fed to goats

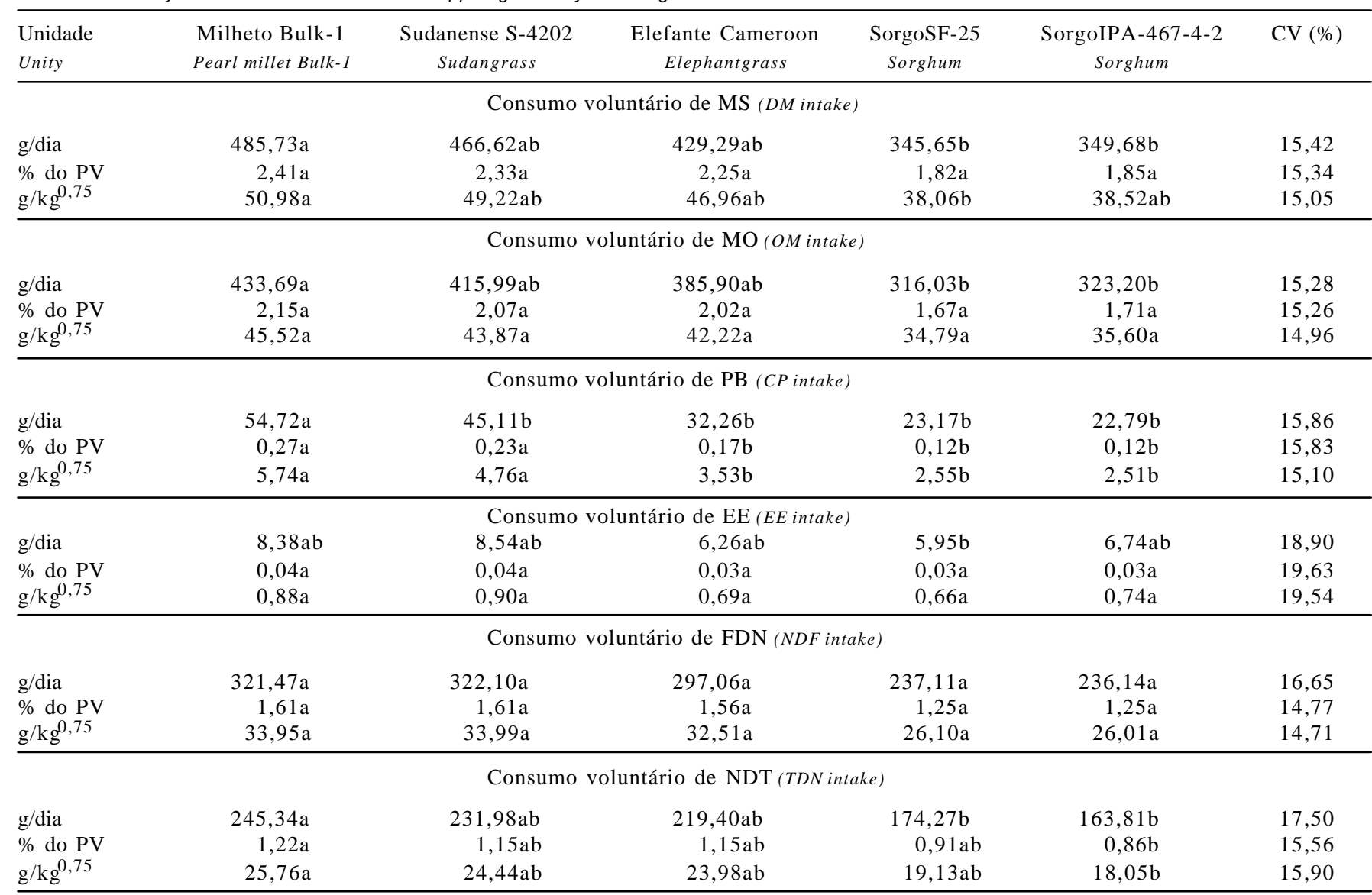

Médias seguidas de mesma letra, na linha, não diferem $(P<0,05)$ pelo teste Tukey.

Means followed by the same letter in the same row do not differ $(P<0.05)$ by Tukey test.

forragem é primordial na promoção de mudanças de consumo da forragem em função da oferta de concentrados. Conforme esses autores, quando a razão DMO/PB é alta (>7), pequenas quantidades de suplementos protéicos podem aumentar o consumo da forragem e maiores quantidades de suplementos energéticos (principalmente ricos em amido) podem promover o efeito contrário. Confirmando essas afirmativas, Kozloski et al. (2006) forneceram milho em grão, em níveis de 0,5 a $1,5 \%$ do PV, a ovinos consumindo feno de capimelefante e constataram reduções de 38,64 e 38,85\%, respectivamente nos consumos de MS e de FDN dos fenos.

As maiores relações DMO/PB dos fenos avaliados foram obtidas para os cultivares de sorgo SF-25 e IPA-4674-2 (9,89 e 10,34), assim como os menores consumos de MS. Por outro lado, as menores relações DMO/PB foram observadas nos fenos de milheto e sorgo sudanense $(5,50$ e 6,56), para os quais obtiveram-se os maiores consumos.

As baixas concentrações de PB dos fenos dos sorgos SF-25 e IPA-467-4-2 (5,64 e 5,04\%), associadas aos baixos consumos desses fenos, parecem respaldar as afirmações de Nolan \& Leng (1989), que relacionam a redução de consumo de MS por ruminantes consumindo forragens com baixos conteúdos de $\mathrm{PB}$, à baixa disponibilidade de aminoácidos nos tecidos. Hogan \& Weston (1981) ressaltaram a ocorrência de limitações da síntese de proteína microbiana quando a relação DMO/PB excede 10. Em outra perspectiva, Coleman et al. (2001), avaliando o consumo de diversos fenos por caprinos, concluíram que as medidas de resistência à degradação (tempo de ruminação e taxa de passagem) foram mais bem relacionadas ao consumo de MS que simples constituintes da composição química da forragem.

Os consumos voluntários de PB (\%PV) evidenciaram diferenças significativas $(\mathrm{P}<0,05)$ para os fenos de milheto e sorgo sudanense, que foram superiores ao capim-elefante e aos sorgos SF-25 e IPA-467-4-2 (Tabela 2). As diferenças são justificadas pelos consumos de MS e pelas maiores concentrações de PB do milheto e do sorgo sudanense. Kozloski et al. (2006) verificaram consumos de PB de feno de capim-elefante anão de 57,34 g/dia no nível de oferta de MS de 2,25\% do PV e Aguiar et al. (2001), de 43,76 g/dia para feno de capim-elefante colhido aos 63 dias, ambos bem superiores aos consumos observados na pesquisa. 
Os consumos de FDN não diferiram entre os fenos e variaram de 236,14 a 322,10 g/dia, representando 1,25 a $1,61 \%$ do PV dos caprinos (Tabela 2).

Aguiar et al. (2001) obtiveram consumos mais expressivos de FDN com fenos de capim-elefante colhido de 30 a 90 dias de idade, variando de 1,84 a $2,72 \%$ do PV de ovinos, mas as gramíneas apresentaram relação F/C média de 1,22 e os fenos permaneceram armazenados por menos tempo. Os consumos de FDN para os fenos de sorgo sudanense $(1,61 \% \mathrm{PV})$ e milheto $(1,61 \% \mathrm{PV})$ foram superiores aos relatados por Cherney et al. (1990a), que obtiveram, respectivamente, 1,51 e 1,46\% do PV, para fenos das mesmas espécies.

Mertens (1987) sugeriu que o consumo de FDN da forragem é limitado a aproximadamente 1,1-1,2\%PV. Nesta pesquisa e em diversos outros trabalhos (Hall et al., 1990; Matejovski \& Sanson, 1995; Aguiar et al., 2001) com fenos de gramíneas tropicais, obtiveram-se valores superiores de consumo de FDN.

Segundo Moore (1994), o impedimento do consumo de FDN não se aplica a forragens ofertadas de forma exclusiva, pois talvez existam frações da FDN, na mesma ou em distintas espécies, com variações nas taxas de degradação e passagem. Confirmando essas hipóteses, Kozloski et al. (2006) avaliaram o nível de consumo do feno de capimelefante anão e sua relação com o valor nutritivo da forragem e constataram elevados consumos de MS e FDN por ovinos, atribuídos à alta digestibilidade da parede celular e à grande renovação de conteúdo no trato digestivo.

O consumo voluntário de NDT, tanto em \% PV como em relação ao peso metabólico, só diferiu significativamente $(\mathrm{P}<0,05)$ entre o feno de milheto e o do sorgo IPA-467-4-2.

As digestibilidades aparentes da MS dos fenos não diferiram significativamente e apresentaram variações de 49,87 a 55,90\% (Tabela 3). Mulligan et al. (2001) listaram o conteúdo de proteína e o nível de consumo como fatores que podem afetar a digestibilidade do feno. Maiores quantidades de tecidos vasculares lignificados e esclerenquimáticos proporcionam também menores taxas de digestibilidade (Wilson \& Hatfield, 1997).

As digestibilidades da MS e MO do feno de capimelefante obtidas estão de acordo com os valores encontrados por Morais et al. (2004), de 57,16 e 60,95\%, respectivamente, para fenos da mesma espécie ofertados na proporção de 2,25\% PV. Para fenos de sorgos e palhadas, Distel et al. (1994) e Blummel et al. (2003) descreveram valores de digestibilidades da MS de 52,85 e 49,4\%, respectivamente, próximos aos índices obtidos no trabalho para o sorgo IPA467-4-2. Quanto à DMS do feno de sorgo sudanense, Barriere et al. (2003) obtiveram índices de 55,9\% e, para o milheto, Cherney et al. (1990b) apresentaram valores superiores aos registrados nesta pesquisa $(64,35 \%)$.

A digestibilidade da PB (DPB) também não diferiu significativamente entre os fenos de milheto, sorgo sudanense, capim-elefante e sorgo SF-25 (Tabela 3). Coleman et al. (2001) relataram DPB média de 53,3\% para diversos fenos de forrageiras tropicais perenes. Gonçalves et al. (2003) obtiveram DPB de 47,0 a 61,0\% para fenos de tifton, com 84 e 28 dias, respectivamente. Quanto à DPB de feno de capim-elefante anão, Morais et al. (2004) obtiveram valor médio de $51,48 \%$, inferior ao percentual obtido nesta pesquisa. As baixas DPB observadas para os fenos dos sorgos podem ser explicadas pelas alterações químicas promovidas pelo maior período para atingir o ponto de cura (3 dias), pelo longo período de armazenamento, pela baixa concentração de PB, que aumenta o efeito do nitrogênio metabólico fecal, e pelo alto conteúdo de lignina da forragem original.

A DFDN diferiu significativamente entre os fenos do milheto e do sorgo IPA-467-4-2 (Tabela 3). Coleman et al. (2001) encontraram valor médio de 58,3\% para a DFDN de quatro fenos de gramíneas tropicais em ensaio com caprinos.

Barriere et al. (2003) consideram as plantas forrageiras como a base da nutrição de ruminantes e a digestibilidade da parede celular destas plantas como o principal fator limitante de seus valores nutritivos. Esses autores apontaram a lignina como principal fator para a redução da digestibilidade da parede celular.

Morais et al. (2004) registraram DFDN média do feno de capim-elefante anão igual a $62,01 \%$, enquanto, nesta pesquisa, foi obtido valor de $60,84 \%$. Gomes et al. (1994) verificaram DFDN de 67,4 e 48,5\%, respectivamente, para fenos de capim-elefante Napier com 1,0 m e Cameroon com 3,0 m e Aguiar et al. (2001), de 65,11\% para o mesmo feno produzido com gramíneas cortadas aos 63 dias.

Valores de DFDN do milheto e do sorgo sudanense bem superiores (espectivamente, 77,35 e 77,65\%) aos obtidos neste trabalho foram reportados por Cherney et al. (1990a), mas esses fenos apresentaram de 77,7 e 86,6\% de folhas, como resultado de cortes precoces, plantios adensados e fertilizações. Por outro lado, valores inferiores aos obtidos neste estudo foram descritos por Blummel et al. (2003), que encontraram DFDN para o sorgo e milheto de, respectivamente, 54,3 e 54,0\%.

Como o valor nutritivo e o consumo são fatores determinantes da qualidade da forragem (Sollenberger \& Cherney, 1995), é importante considerar os resultados obtidos com os fenos triturados em relação a essas características. Comparando os fenos triturados de milheto e de sorgo sudanense aos fenos dos sorgos SF-25 e IPA-467-4-2, verificaram-se maiores concentrações e consumos de $\mathrm{PB}$ para os fenos de milheto e sorgo sudanense. 
Tabela 3 - Digestibilidade dos nutrientes e nutrientes digestíveis totais (NDT) de fenos triturados de gramíneas tropicais Table 3 - Digestibility of nutrients and total digestible nutrients (TDN) of different chopped grass hays fed to goats

\begin{tabular}{|c|c|c|c|c|c|c|}
\hline \multirow[b]{2}{*}{ Item } & \multicolumn{5}{|c|}{$\begin{array}{c}\text { Digestibilidade (\%) } \\
\text { Digestibility }(\%)\end{array}$} & \multirow[b]{2}{*}{$\mathrm{CV}(\%)$} \\
\hline & $\begin{array}{l}\text { Milheto Bulk-1 } \\
\text { Pearl millet Bulk-1 }\end{array}$ & $\begin{array}{c}\text { Sudanense S- } 4202 \\
\text { Sudangrass }\end{array}$ & $\begin{array}{c}\text { Elefante Cameroon } \\
\text { Elephantgrass }\end{array}$ & $\begin{array}{c}\text { Sorgo SF-25 } \\
\text { Sorghum }\end{array}$ & $\begin{array}{l}\text { Sorgo IPA-467-4-2 } \\
\text { Sorghum }\end{array}$ & \\
\hline $\operatorname{DMS}(D M D)$ & $55,90 \mathrm{a}$ & $54,77 \mathrm{a}$ & $56,88 \mathrm{a}$ & $54,21 \mathrm{a}$ & $49,87 \mathrm{a}$ & 8,38 \\
\hline $\mathrm{DMO}(O M D)$ & $60,15 \mathrm{ab}$ & $57,28 \mathrm{ab}$ & $60,54 \mathrm{a}$ & $55,78 \mathrm{ab}$ & $52,13 b$ & 7,64 \\
\hline $\mathrm{DPB}(C P D)$ & $59,11 \mathrm{a}$ & $45,08 \mathrm{ab}$ & $53,24 \mathrm{a}$ & $44,87 \mathrm{ab}$ & $37,73 b$ & 16,22 \\
\hline $\mathrm{NDT}(T D N)$ & $50,54 \mathrm{a}$ & $49,52 \mathrm{a}$ & $51,30 \mathrm{a}$ & $50,48 \mathrm{a}$ & $46,96 a$ & 8,42 \\
\hline
\end{tabular}

Médias seguidas de mesma letra, na linha, não diferem $(P>0,05)$ pelo teste Tukey.

Means followed by the same letter in the same row do not differ $(P>0.05)$ by Tukey test.

Esses resultados são reflexos naturais da fase de desenvolvimento ou da maturidade das forrageiras utilizadas na confecção dos fenos, visto que o milheto e o sorgo sudanense foram colhidos, respectivamente, aos 50 e 62 dias e os cultivares de sorgo aos 83 e 91 dias de idade. Além das variações morfológicas entre as espécies, as idades de colheita também contribuíram para a maior relação F/C do milheto e do sorgo sudanense $(0,64$ e 0,62$)$ em relação aos cultivares de sorgo $(0,48$ e 0,38$)$ (Aguiar, 2005). Do ponto de vista nutricional, as folhas, porção mais nobre dos vegetais, são as partes mais ricas em nutrientes, enquanto os colmos são de mais baixa qualidade (Van Soest, 1994).

Os fenos de capim-elefante foram classificados em posição intermédia quando avaliados a concentração de PB e os consumos de MS e PB. Na seleção de uma forragem, não se deve considerar somente a qualidade, pois outras características, como adaptação, rendimento e valor forrageiro, são importantes (Posler et al., 1983).

Para os agricultores familiares do semi-árido nordestino, que têm limitações de áreas de cultivo, as produções de feno obtidas com os cultivares de sorgo SF-25 e IPA-467-4-2, de 10,65 e 10,85 t/ha/corte (Aguiar, 2005), , respectivamente, mesmo com qualidade inferior, podem consistir em alternativas com suplementação de concentrados ou associações com a palma forrageira ou resíduos da agroindústria (caju, melão, abacaxi, cevada). Destaca-se ainda o longo período (dois anos) de armazenamento dos fenos, fato que evidencia suas aptidões como reservas forrageiras estratégicas para os períodos de estiagem.

Entretanto, são necessários novos estudos sobre a influência de suplementos no consumo e na utilização dos fenos triturados. Também é importante o desenvolvimento de pesquisas sobre as idades de corte, o período e as condições de armazenamento dos fenos, assim como sobre os efeitos dessas forragens no desempenho animal.

\section{Conclusões}

Considerando aspectos do valor nutritivo e do consumo, os fenos triturados das cinco gramíneas avaliadas apresentaram indicativos de qualidade aproximados. Todavia, o consumo de MS (g/dia) para o feno de milheto foi maior que para os fenos dos sorgos forrageiros, provavelmente em virtude do maior consumo voluntário de PB.

\section{Literatura Citada}

AGUiAR, E.M. Produção, valor nutritivo e consumo voluntário de fenos triturados de gramíneas tropicais. Recife: Universidade Federal Rural de Pernambuco, 2005. 114p. Tese (Doutorado em Zootecnia) - Universidade Federal Rural de Pernambuco, 2005.

AGUIAR, E.M.; LIMA, G.F.C.; PAZ, L.G. Forage quality evaluation of chopped elephantgrass hay through intake and digestibility trial. In: INTERNATIONAL GRASSLAND CONGRESS, 19., 2001, São Pedro. Proceedings... São Pedro: Fundação de Estudos Agrários Luiz de Queiroz, 2001. p.734-736.

BARRIÈRE, Y.; GUILLET, C. GOFFNER, D. et al. Genetic variation of breeding strategies for improved cell wall digestibility in annual forage crops. A review. Animal Research, v.52, p.193-228, 2003.

BLÜMMEL, M.; ZERBINI, E.; REDDY, B.V.S. et al. Improving the production and utilization of sorghum and pearl millet as livestock feed: methodological problems and possible solutions. Field Crops Research, v.84, p.123-142, 2003.

CAMURÇA, D.A.; NEIVA, J.N.M.; PIMENTEL, J.C.M. et al. Desempenho produtivo de ovinos alimentados com dietas à base de feno de gramíneas tropicais. Revista Brasileira de Zootecnia, v.31, n.4, p.1-16, 2002.

CAVALCANTE, A.C.R.; PEREIRA, O.G.; VALADARES FILHO, S.C. et al. Dietas contendo silagem de milho (Zea maiz L.) e feno de capim-tifton 85 (Cynodon spp.) em diferentes proporções para bovinos. Revista Brasileira de Zootecnia v.33, n.6, p.2394-2402, 2004 (supl. 3).

CHERNEY, D.J.R.; PATTERSON, J.A.; JOHNSON, K.D. Digestibility and feeding value of pearl millet as influenced by the brown-midrib, low-lignin trait. Journal of Animal Science, v.68, p.4345-4351, 1990a.

CHERNEY, D.J.R.; MERTENS, D.R.; MOORE, J.E. Intake and digestibility by wethers as influenced by forage morphology at 
three levels of forage offering. Journal of Animal Science, v.68, p.4387-4399, 1990b.

COLEMAN, S.W.; HART, S.P.; SAHLU, T. Prediction of intake of hay differing in species and maturity by goats. In: INTERNATIONAL GRASSLAND CONGRESS, 21., 2001, São Pedro. Proceedings... São Pedro: Fundação de Estudos Agrários Luiz de Queiroz, 2001. p.366-369.

DISTEL, R.A.; VILLALBA, J.J.; LABORDE, H.E. Effects of early experience on voluntary intake of low-quality roughage by sheep. Journal of Animal Science, v.79, p.1191-1195, 1994.

GOMES, B.V.; QUEIROZ, A.C.; FONTES, C.A.A. et al. Estudo das características físico-química de fenos e palha. I. Efeitos sobre a ingestão, digestibilidade aparente e taxa de passagem da matéria seca, $\mathrm{pH}$ e concentração de amônia ruminal. Revista Brasileira de Zootecnia, v.23, n.3, p.352-365, 1994.

GONÇALVES, G.D.; SANTOS, G.T.; JOBIM, C.C. et al. Determinação do consumo, digestibilidade e frações protéicas e de carboidratos do feno de tifton 85 em diferentes idades e corte. Revista Brasileira de Zootecnia, v.32, n.4, p.804$813,2003$.

HALL, K.L.; GOETSH, A.L.; FORSTER JR., L.A. Effects of buffer or dimethionine with different amounts of supplemental corn on feed intake and nutrient digestion by Holstein steers consuming bermudagrass hay. Journal of Animal Science, v.68, p.1674-1682, 1990.

HODGSON, J. Grazing management: science into practice. Longman handbooks in Agriculture. Harlow: Essex, 1990. 466p.

HOGAN J.P.; WESTON, R.H. Laboratory methods for protein evaluation. In:WHEELER, J.L.; MOCHRIE R.D. (Eds.) Forage evaluation: concepts and techniques. Netley: Griffin Press, 1981. p.75-87.

KOZLOSKI, G.V.; SANCHEZ, L.M.B.; CADORIN JR., R.L. et al. Intake and digestion by lambs fed just dwarf elephant grass hay (Pennisetum purpureum Schum. cv. Mott) or supplemented with urea and different levels of cracked corn grain. Animal Feed Science and Technology, v.125, n.1, p.111-122, 2006.

LIMA, G.F.C.; AGUIAR, E.M.; MACIEL, F.C. et al. Produção de fenos alternativos para a agricultura familiar no semi-árido nordestino. In: SIMPÓSIO PARAIBANO DE ZOOTECNIA, 3., 2002, Areia. Anais... Areia: Universidade Federal da Paraíba, 2002. p.1-13.

MATEJVOSKY, K.M.; SANSON, D.W. Intake and digestion of low, medium and high quality grass hays by lambs receiving increasing levels of corn supplementation. Journal of Animal Science, v.73, n.7, p.2156-2163, 1995.

MERTENS, D.R. Predicting intake and digestibility using mathematical models of ruminal function. Journal of Animal Science, v.64, n.7, p.1548-1558, 1987.

MOORE, J.E. Procedure for determining voluntary intake and nutrient digestibility of hay with sheep. Gainesville: University of Florida, 1981. 8p.

MOORE, J.E. Forage quality indices: development and application. In: FAHEY, G.C. (Ed.) Forage quality, evaluation and utilization. Madison: American Society Agronomy, Crop Science Society American, Soil Science Society American, 1994. p.967-998.

MOORE, J.E.; KUNKLE, W.K. Improving forage supplementation programs for beef cattle. In: ANNUAL BEEF CATTLE SHORT COURSE, 40., 1995, Gainesville. Proceedings... Gainesville: University of Florida, 1995. p.65-74.
MORAIS, J.A.S.; KOZLOSKI, G.V.; SANCHEZ, L.M.B. et al. Nível de consumo e sua relação cinética da digestão do feno de capimelefante anão (Pennisetum purpureum Schum. cv. Mott) em ovinos. In: REUNIÃO ANUAL DA SOCIEDADE BRASILEIRA DE ZOOTECNIA, 41., 2004, Campo Grande. Anais... Campo Grande: Sociedade Brasileira de Zootecnia, 2004. (CD-ROM)

MOREIRA, A.L.; PEREIRA, O.G.; GARCIA, R. et al. Consumo e digetibilidade aparente dos nutrientes da silagem de milho e dos fenos de alfafa e de capim-coastcross, em ovinos. Revista Brasileira de Zootecnia, v.30, n.3, p.1099-1105, 2001 (supl. 1).

MULLIGAN, F.J.; CAFFREY, P.J.; RATH, M. et al. The effect of dietary crude protein and hay intake level on the true and apparent digestibility of hay. Livestock Production Science, v.68, p.41-52, 2001.

NOLAN, J.V.; LENG, R.A. Manipulation of the rumen to increase ruminant production. In: FEEDING STRATEGIES FOR IMPROVING PRODUCTIVITY OF RUMINANT LIVESTOCK IN DEVELOPING COUNTRIES, 1989, Vienna. Proceedings... Vienna: FAO/IAEA, 1989. p.13-17.

POSLER, G.L.; BOLSEN, K.K.; NUWANYAKPA, M.Y. Summer annual forages for livestock production in Kansas. Kansas: Agricultural Experiment Station, Kansas State University, 1983. 18p. (Bulletin, 642).

REID, R.L.; JUNG, G.A.; THAYNE, W.V. Relationships between nutritive quality and fiber components of cool season and warm season forages: a retrospective study. Journal of Animal Science, v.66, p.1275-1291, 1988.

REIS, R.A.; MOREIRA, A.L.; PEDREIRA, M.S. Técnicas para produção e conservação de fenos de forrageiras de alta qualidade. In: SIMPÓSIO SOBRE PRODUÇÃO E UTILIZAÇÃO DE FORRAGENS CONSERVADAS, 1., Maringá.Anais... Maringá: Universidade Estadual de Maringá, 2001. p.1-39.

STASTICAL ANALYSIS SYSTEMS - SAS. User's guide: version 6, 4.ed. Cary: 1995, v.2. 943p.

SILVA, D.J.; QUEIROZ, A.C. Análises de alimentos (métodos químicos e biológicos). Viçosa, MG: Editora UFV, 2002. 253p.

SNIFFEN, C.J.; O'CONNOR, J.D.; Van SOEST, P.J. A net carbohydrate and protein system for evaluating cattle diets. II. Carbohydrate and protein availability. Journal of Animal Science, v.70, p.3562-3577, 1992.

SOLLENBERGER, L.E.; CHERNEY, D.J.R. Evaluating forage production and quality. In: BARNES, R.F.; MILLER, D.A.; NELSON, C.J. (Eds.) Forages: the science of grassland agriculture. Ames: University Press, 1995. v.2, p.97-110.

Van SOEST, P.J.; ROBERTSON, J.B.; LEWIS, B.A. Methods for dietary fiber neutral detergent and nonstarch polysaccharides in relation to animal nutrition. Journal of Dairy Science, v.74, n.10, p.3583-3597, 1991.

Van SOEST, P.J. Nutritional ecology of the ruminant. 2.ed. New York: Cornell University Press, 1994. 476p.

WILSON, J.R.; HATFIELD, R.D. Structural and chemical changes of cell wall types during stem development: consequences for fibre degradation by rumen microflora. Australian Journal of Agriculture Research, v.18, n.2, p.165-180, 1997. 